\title{
Intracellular glutathione production, but not protein glycation, underlies the protective effects of captopril against 2-deoxy-D-ribose-induced $\beta$-cell damage
}

\author{
GWANPYO KOH $^{1,2}$, EUN-JIN YANG ${ }^{1}$, JI YOUNG KIM ${ }^{2}$, JONGHOON HYUN ${ }^{1}$, \\ SOYEON YOO ${ }^{2}$ and SANG AH LEE ${ }^{1,2}$ \\ ${ }^{1}$ Department of Internal Medicine, Jeju National University School of Medicine; ${ }^{2}$ Department of Internal Medicine, \\ Jeju National University Hospital, Jeju-si, Jeju 690-767, Republic of Korea
}

Received September 1, 2014; Accepted June 22, 2015

DOI: $10.3892 / \mathrm{mmr} .2015 .4047$

\begin{abstract}
Our previous study reported that both oxidative stress and protein glycation were the principal mechanisms underlying 2-deoxy-D-ribose (dRib)-induced pancreatic $\beta$-cell damage. The aim of the present study was to investigate the effects of captopril on dRib-induced damage in pancreatic $\beta$-cells, as well as to determine the mechanisms underlying these effects. Treatment with dRib increased the levels of cytotoxicity, apoptosis, and intracellular reactive oxygen species in Syrian hamster insulinoma HIT-T15 cells; however, pretreatment with captopril significantly inhibited the effects of dRib. The intracellular levels of reduced and oxidized glutathione were depleted following treatment with dRib; however, these levels were restored following HIT-T15 cell treatment with captopril. In rat islets, dRib stimulation suppressed the mRNA expression levels of insulin, and pancreatic and duodenal homeobox 1, as well as insulin content; however, these effects were dose-dependently reversed by treatment with captopril. Treatment with buthionine sulfoximine, an inhibitor of intracellular glutathione biosynthesis, inhibited the protective effects of captopril on dRib-mediated glutathione depletion and cytotoxicity in HIT-T15 cells. Following incubation with albumin, dRib increased the formation of dicarbonyl and advanced glycation end products. Treatment with captopril did not inhibit the $\mathrm{dRib}$-induced increase in production of dicarbonyl and advanced glycation end products. In conclusion, treatment with captopril reversed $\mathrm{dRib}$-induced oxidative damage and suppression of insulin expression in $\beta$-cells. The mechanism underlying the protective effects of captopril may involve increased intracellular glutathione production, rather than protein glycation.
\end{abstract}

Correspondence to: Professor Gwanpyo Koh, Department of Internal Medicine, Jeju National University School of Medicine, 15 Aran 13-gil, Jeju-si, Jeju 690-767, Republic of Korea

E-mail: okdom@jejunu.ac.kr

Key words: captopril, 2-deoxy-D-ribose, glutathione, protein glycation, pancreatic $\beta$ cell

\section{Introduction}

Sugars that contain aldehyde groups and are oxidized to carboxylic acids are termed reducing sugars. Among reducing sugars, 2-deoxy-D-ribose (dRib) has the highest reactivity to induce protein glycation (1). Our previous study reported that dRib causes cellular damage by increasing the levels of oxidative stress and protein glycation in pancreatic $\beta$-cells (2). Oxidative stress is an important mechanism underlying $\beta$-cell failure in type 2 diabetes (3), and protein glycation mediates chronic diabetic complications (4). High-glucose stimulation increases the levels of intracellular reactive oxygen species (ROS) and protein glycations in pancreatic $\beta$-cells, which is a lengthy process. However, dRib promptly induces oxidative damage and protein glycation in a short time (2). Therefore, $\mathrm{dRib}$ may be used as a stimulant in place of glucose in experimental studies of islet biology and diabetic complications.

Captopril is an angiotensin-converting enzyme inhibitor (ACEI) used in the treatment of hypertension. In large randomized controlled trials, ACEIs exerted both diabetes-preventive and blood pressure-lowering effects (5). These preventive effects may be associated with the ACEI-induced preservation of $\beta$-cell function, due to the fact that insulin secretion is an important mechanism underlying the progression from glucose intolerance to diabetes (6). Previous studies have suggested that captopril decreases oxidative stress in cellular (7) and animal (8) models. The ROS-scavenging activity of the sulfhydryl group in the captopril structure is thought to be responsible for its antioxidant properties (9).

The aim of the present study was to examine whether captopril is able to prevent dRib-induced oxidative injury and insulin suppression in pancreatic $\beta$-cells. In addition, the mechanism underlying the antioxidative effects of captopril on $\mathrm{dRib}$-induced $\beta$-cell damage was investigated.

\section{Materials and methods}

Materials. Captopril, buthionine sulfoximine (BSO), dihydrorhodamine 123 (DHR 123), Ficoll, sodium azide, Girard-T reagent, 5,5-dimethyl-1-pyrroline-N-oxide, $\mathrm{FeSO}_{4}$, and $\mathrm{H}_{2} \mathrm{O}_{2}$ were purchased from Sigma-Aldrich (St Louis, MO, USA). 
dRib, HEPES, guanidine hydrochloride, potassium phosphate monobasic, and potassium phosphate dibasic were purchased from Amresco, LLC (Solon, OH, USA). Hydrochloric acid and ethanol were purchased from Merck Millipore (Darmstadt, Germany). RPMI-1640, Dulbecco's phosphatebuffered saline (DPBS), trypsin, penicillin, streptomycin, and TRIzol ${ }^{\circledR}$ reagent were purchased from Gibco Life Technologies (Carlsbad, CA, USA). Collagenase P and Hank's balanced salt solution (HBSS) were purchased from Roche Diagnostics GmbH (Mannheim, Germany). Fetal bovine serum (FBS) was purchased from GE Healthcare Life Sciences (Logan, UT, USA). All culture dishes and tubes were purchased from BD Biosciences (Franklin Lakes, NJ, USA).

Cell culture. Syrian hamster insulinoma HIT-T15 cells were obtained from the Korean Cell Line Bank (Seoul, Korea). The cells were cultured at $37^{\circ} \mathrm{C}$ in an atmosphere containing $5 \% \mathrm{CO}_{2}$ and $95 \% \mathrm{O}_{2}$, in RPMI-1640 medium supplemented with $10 \%$ FBS, $100 \mathrm{mg} / \mathrm{ml}$ penicillin, and $100 \mathrm{mg} / \mathrm{ml}$ streptomycin. The HIT-T15 cells were separated by trypsinization and subcultured until reaching $\sim 70 \%$ confluence. Two days following subculture, the culture medium was discarded and replaced with RPMI-1640 supplemented with 10\% FBS, and the cells were pretreated with $0.1,0.5$, or $1 \mathrm{mM}$ captopril and/or $200 \mu \mathrm{M}$ BSO for $30 \mathrm{~min}$, prior to the addition of 30 or $50 \mathrm{mM}$ dRib to the medium. The cultures were then further incubated for 6 or $24 \mathrm{~h}$.

Islet isolation and culture. The method of islet isolation and culture was carried out as previously described (10). Sprague Dawley rats (age, 6-8 weeks) were provided by Orient Bio Inc. (Seongnam, Korea). The rats were housed under a controlled temperature $\left(23^{\circ} \mathrm{C}\right), 50 \%$ humidity and a $12 \mathrm{~h}$ light-dark cycle with ad libitum access to water and food. A total of 10 rats were sacrificed by cervical dislocation, an incision was made into the abdomen, and 9-10 $\mathrm{ml}$ collagenase $\mathrm{P}$ in $1 \mathrm{mg} / \mathrm{ml} \mathrm{HBSS}$ was injected into the pancreas via the bile duct. The distended pancreas was then removed for digestion at $37^{\circ} \mathrm{C}$ for $\sim 12 \mathrm{~min}$, and the tissue samples were separated using a Ficoll gradient. Isolated islets were suspended in RPMI-1640 supplemented with $20 \% \mathrm{FBS}$ and $11.1 \mathrm{mM}$ glucose for $24 \mathrm{~h}$ prior to experimentation. Thereafter, the medium was replaced by fresh RPMI-1640 supplemented with $10 \% \mathrm{FBS}$, and $10 \mathrm{mM}$ dRib was added to the medium following pretreatment with $0.1,0.5$, or $1 \mathrm{mM}$ captopril for $30 \mathrm{~min}$. The cultures were incubated for $6 \mathrm{~h}$. The present study was approved by the Institutional Animal Care and Use Committee of Jeju National University (Jeju, Korea).

Assessment of cell viability. The HIT-T15 cells were cultured in 24-well plates at a density of $1 \times 10^{5}$ cells/well. The cells were then incubated with $30 \mathrm{mM}$ dRib for $24 \mathrm{~h}$, with or without captopril. The cells were subsequently harvested and stained with $0.4 \%$ trypan blue (Sigma-Aldrich) for $5 \mathrm{~min}$. The cells were transferred to a hemocytometer (Marienfield-Superior, Baden-Württemberg, Germany), and both the dead cells that did not exclude the dye, and the viable cells that excluded the dye were counted. The dead and viable cells were counted using an inverted fluorescence microscope (Olympus IX50; Olympus, Tokyo, Japan). The results were expressed as the percentage of viable cells in total cell population.
Flow cytometry to assess apoptosis. The HIT-T15 cells were stained with fluorescein isothiocyanate (FITC)-conjugated Annexin $\mathrm{V}$ and propidium iodide (PI) using a Vybrant Apoptosis Assay kit \#2, according to the manufacturer's instructions (Molecular Probes Life Technologies, Carlsbad, CA, USA). Briefly, the HIT-T15 cells were cultured in six-well plates at a density of $5 \times 10^{5}$ cells/well. The cells were then treated with $50 \mathrm{mM}$ dRib and captopril for $24 \mathrm{~h}$. Following gentle washing with PBS, the cells were collected by trypsinization and centrifugation. The cell pellets were resuspended in PBS and centrifuged $\left(200 \mathrm{x} \mathrm{g}\right.$ for $5 \mathrm{~min}$ at $\left.4^{\circ} \mathrm{C}\right)$, prior to being resuspended and incubated with FITC-conjugated Annexin V and PI staining solution at room temperature for $15 \mathrm{~min}$. The stained cells were analyzed using a FACSCalibur fluorescence-activated cell sorter (BD Bioscience, San Jose, CA, USA), and the data were analyzed using CellQuest software (BD Bioscience). A total of $1 \times 10^{4}$ cells were evaluated for each sample.

Assessment of the intracellular levels of ROS. Intracellular ROS levels were investigated using a DHR 123 dye. Cellular fluorescence intensity is directly correlated with intracellular ROS levels. The HIT-T15 cells were plated in 24-well culture plates at a density of $5 \times 10^{5}$ cells/well. The cells were treated with $50 \mathrm{mM} \mathrm{dRib}$ and $1 \mathrm{mM}$ captopril for $\leq 6 \mathrm{~h}$, due to the possibility of extensive cell death interfering with ROS measurements. A total of $5 \mu \mathrm{M}$ DHR 123 was added to the cell cultures $30 \mathrm{~min}$ prior to harvesting. The cells were then washed twice with PBS and harvested using $0.05 \%$ trypsin. The cells were then centrifuged and resuspended in PBS, and the intracellular levels of ROS were measured using a FACScan instrument (BD Bioscience). A total of $1 \times 10^{4}$ cells were analyzed per sample. The data were calculated as the mean fluorescence intensity, and expressed as the fold difference, as compared with control untreated cells.

Measurement of the intracellular levels of glutathione. The intracellular levels of glutathione were measured using a Glutathione Assay kit (Cayman Chemical, Ann Arbor, MI, USA) according to an enzymatic recycling method using glutathione reductase. The HIT-T15 cells were cultured in 6-well plates at a density of $5 \times 10^{5}$ cells/well. The cells were treated as described above prior to being washed with ice-cold DPBS and sonicated using a Vibra Cell sonicator (Sonics \& Materials, Danbury, CT, USA) at $30 \%$ of the maximal amplitude, and were subsequently centrifuged at $10,000 \times \mathrm{g}$ for $15 \mathrm{~min}$. The resulting supernatants were used to measure glutathiones. Exclusive measurement of oxidized glutathione (GSSG) is accomplished by first derivatizing reduced glutathione (GSH) as described by the manufacturer of the Glutathione Assay kit. The amount of GSH can also be determined by subtracting the quantity of GSSG from the total amount of glutathiones. The glutathione concentrations were expressed as $\mu \mathrm{M} / 1$ in reference to a standard curve.

Assessment of reactive dicarbonyl and advanced glycation end product (AGE) formation. The reaction mixture contained $10 \mathrm{mg} / \mathrm{ml}$ bovine serum albumin (BSA; Gibco Life Technologies), $0.02 \%$ sodium azide, and $100 \mathrm{mM} \mathrm{CuSO}_{4}$ in $100 \mathrm{mM}$ sodium phosphate buffer (pH 7.4), with a final volume 
of $4 \mathrm{ml}$. The mixture was incubated with 10,30 , or $50 \mathrm{mM}$ $\mathrm{dRib}$ and $1 \mathrm{mM}$ captopril at $37^{\circ} \mathrm{C}$ for three days in capped polystyrene tubes. All incubations were carried out in quadruplicate. The incubated sample mixtures were dialyzed against $100 \mathrm{mM}$ sodium phosphate buffer ( $\mathrm{pH}$ 7.4) for $48 \mathrm{~h}$, in order to remove unbound dRib and any other impurities. The sample mixtures were then stored at $\leq 0^{\circ} \mathrm{C}$ prior to being assayed for dicarbonyl or AGE fluorescence.

The levels of albumin-attached dicarbonyls were measured using the Girard-T reagent as previously described (11). Briefly, the reaction mixture containing $60 \mathrm{ml}$ sample or each standard solution, $20 \mathrm{ml} 0.5 \mathrm{~N}$ sodium borate ( $\mathrm{pH} 9.2)$, and $20 \mathrm{ml} 0.1 \mathrm{~N}$ Girard-T reagent was incubated at $30^{\circ} \mathrm{C}$ for $10 \mathrm{~min}$. A total of $100 \mathrm{ml}$ 0.1 $\mathrm{N}$ sodium borate ( $\mathrm{pH}$ 9.2) was added to the mixture, and the absorbance was measured at $375 \mathrm{~nm}$ against a zero blank using a UVmini-1240 spectrophotometer (Shimadzu Corporation, Kyoto, Japan). The concentration of the reactive dicarbonyl was calculated by comparison with standard solutions, and was corrected with the total protein concentration. The present study used glyoxal to normalize the data.

AGE fluorescence of the incubation mixture was measured at excitation and emission wavelengths of 350 and $450 \mathrm{~nm}$, respectively, against an unincubated blank containing dRib and captopril using a DTX 880 Multimode Detector fluorescence reader (Beckman Coulter, Inc., Fullerton, CA, USA). Any significant difference observed between the sample and the control was used as an indication of AGE formation.

RNA isolation and reverse transcription-quantitative polymerase chain reaction ( $R T-q P C R)$. Rat islets were pre-treated with captopril for $30 \mathrm{~min}$ at $0.1,0.5$, or $1.0 \mathrm{mM}$, and then cultured with $10 \mathrm{mM}$ dRib for $6 \mathrm{~h}$. Total RNA was isolated using TRIzol ${ }^{\circledR}$, according to the manufacturer's instructions. RNA isolation was carried out in an RNase-free environment. A total of $4 \mathrm{mg}$ aliquots of RNA were reverse transcribed using MuLV reverse transcriptase (Promega Corporation, Madison, WI, USA), oligo (dT)15 primer, dNTP (0.5 mM) and 1 unit RNase inhibitor (Promega Corporation). RT-qPCR was performed using a 2 SYBR Green PCR Master Mix (Bio-Rad Laboratories, Inc., Hercules, CA, USA) and an $\mathrm{iQ}^{\mathrm{TM}} 5$ Multicolor Real-Time PCR Detection system (Bio-Rad Laboratories, Inc.). The PCR was performed to amplify the synthesized cDNA in the presence of specific primers, for 40 cycles at $95^{\circ} \mathrm{C}$ for $20 \mathrm{sec}, 60^{\circ} \mathrm{C}$ for $20 \mathrm{sec}$, and $72^{\circ} \mathrm{C}$ for $30 \mathrm{sec}$, with an initial cycle of $95^{\circ} \mathrm{C}$ for $5 \mathrm{~min}$. The PCR reactions were carried out using the following primers for the cDNA sequences: Insulin forward, 5'-GAACGGCTACAA TCTCCGGAGGCA-3', and reverse, 5'-TTCCAGAGGCGG TCGTGGTCACAA-3'; pancreatic and duodenal homeobox 1 (PDX-1) forward, 5'-AGTTTGCAGGCTCGCTGGGAA-3', and reverse, 5'-TTCCACGCGTGAGCTTTGGTGG-3'; and $\beta$-actin forward, 5'-TCCTGGCCTCACTGTCCAC-3', and reverse, 5'-GGGCCGGACTCATCGTACT-3'. All primers were synthesized by Bioneer Corporation (Daejeon, Korea).

Measurement of insulin content. The isolated islets were pre-incubated with $0.1,0.5$ or $1 \mathrm{mM}$ captopril for $30 \mathrm{~min}$, and then stimulated with $10 \mathrm{mM}$ dRib for $6 \mathrm{~h}$. The cells were subsequently harvested and washed twice with cold DPBS. The cells were lysed using a lysis buffer containing $50 \mathrm{mM}$
Tris- $\mathrm{HCl} \mathrm{pH}$ 7.5, $150 \mathrm{mM} \mathrm{NaCl}, 2 \mathrm{mM}$ EDTA, $1 \mathrm{mM}$ ethylene glycol tetraacetic acid, $1 \mathrm{mM} \mathrm{Na} \mathrm{VO}_{4}, 10 \mathrm{mM} \mathrm{NaF}, 1 \mathrm{mM}$ dithiothreitol, $1 \mathrm{mM}$ phenylmethylsulfonylfluoride, $25 \mathrm{mg} / \mathrm{ml}$ aprotinin, $25 \mathrm{mg} / \mathrm{ml}$ leupeptin, and 1\% Nonidet P-40, in order to obtain whole cell protein, which was kept on ice for $30 \mathrm{~min}$. The cell lysates were centrifuged at $15,000 \mathrm{x} \mathrm{g}$ for $15 \mathrm{~min}$ at $4^{\circ} \mathrm{C}$. The supernatant was used to determine the levels of insulin and protein contents. The levels of insulin were determined using an ELISA kit (Mercodia, Uppsala, Sweden) with rat insulin as a standard, according to the manufacturer's instructions. Protein content was measured using a BCA Protein Assay Reagent kit (Pierce Biotechnology, Inc., Rockford, IL, USA). The intracellular insulin content was corrected for total protein content, and expressed as $\mathrm{mg} / \mathrm{mg}$ protein.

Statistical analysis. All data are expressed as the mean \pm standard error. The statistical difference between the groups were analyzed by one-way analysis of variance, followed by Duncan's post hoc and Student's t-test. All analyses were performed using SPSS 14.0 software (SPSS Inc., Chicago, IL, USA). $\mathrm{P}<0.05$ was considered to indicate a statistically significant difference.

\section{Results}

Captopril prevents dRib-triggered cytotoxicity and apoptosis. Trypan blue exclusion demonstrated that a $24 \mathrm{~h}$ incubation of the HIT-T15 cells with $30 \mathrm{mM}$ dRib led to cell death. Conversely, treatment with $0.1,0.5$, or $1 \mathrm{mM}$ captopril inhibited the dRib-triggered cytotoxicity in a dose-dependent manner (Fig. 1). Treatment with $50 \mathrm{mM}$ dRib increased the percentage of apoptotic cells as shown by Annexin $\mathrm{V}$ and PI double staining; however, these changes were reversed by pretreatment with $1 \mathrm{mM}$ captopril (Table I, Fig. 2).

Captopril reverses the $d R i b$-induced increase in the intracellular levels of ROS and glutathione depletion. The flow cytometric analysis using DHR 123 dye determined that $50 \mathrm{mM}$ dRib stimulation for $6 \mathrm{~h}$ increased the levels of ROS by $\sim 12$-fold in the HIT-T15 cells. The addition of $1 \mathrm{mM}$ captopril reversed the $\mathrm{dRib}$-induced increase in intracellular levels of ROS (Table II, Fig. 3). The present study measured the intracellular levels of both GSH and GSSG in order to assess the total levels of glutathione and intracellular redox potential in HIT-T15 cells. A 6 h stimulation with $30 \mathrm{mM}$ dRib decreased the intracellular levels of GSH and GSSG, and preincubation with various concentrations of captopril dose-dependently restored these levels (Fig. 4). However, the intracellular GSH/GSSG ratio did not differ between the treatment conditions.

Captopril restores the dRib-mediated suppression of insulin transcription, and decreases the levels of insulin in rat islets. The present study examined the effects of dRib on the mRNA expression levels of insulin and PDX-1, as well as the insulin content in rat islets. A lower concentration of $\mathrm{dRib}$ and a shorter treatment time were chosen to stimulate the islets due to the fact that cell damage may interfere with mRNA and protein quantification. RT-qPCR was used to quantify the mRNA expression levels of insulin and PDX-1 in the rat 
Table I. Percentages of Annexin V-positive cells in the control and dRib-treated Syrian hamster insulinoma HIT-T15 cells, with or without CAP treatment.

\begin{tabular}{lc} 
Group & Annexin V-positive cells (\%) \\
\hline Control & $8.3 \pm 2.3$ \\
$50 \mathrm{mM} \mathrm{dRib}$ & $56.3 \pm 7.7^{\mathrm{a}}$ \\
$1 \mathrm{mM} \mathrm{CAP}+50 \mathrm{mM} \mathrm{dRib}$ & $20.1 \pm 1.3^{\mathrm{b}}$ \\
\hline
\end{tabular}

Data are expressed as the mean \pm standard error of four independent experiments. ${ }^{a} \mathrm{P}<0.01$, vs. the control group, and ${ }^{\mathrm{b}} \mathrm{P}<0.01$, vs. the $50 \mathrm{mM}$ dRib group, as determined by one-way analysis of variance and Duncan's post hoc test. dRib, 2-deoxy-D-ribose; CAP, captopril.

islets. Stimulation of the isolated rat islets with $10 \mathrm{mM} \mathrm{dRib}$ for $6 \mathrm{~h}$ significantly suppressed the mRNA expression levels of insulin and PDX-1. This suppression was reversed by pretreatment with captopril in a dose-dependent manner (Fig. 5A and B). The intracellular levels of insulin were measured by ELISA. The $6 \mathrm{~h}$ stimulation of the islets with $10 \mathrm{mM} \mathrm{dRib}$ significantly decreased the levels of insulin, and this insulin suppression was dose-dependently attenuated by treatment with captopril (Fig. 5C).

Treatment with BSO inhibits the protective effects of captopril on dRib-induced glutathione depletion and cytotoxicity. BSO is a specific and irreversible inhibitor of glutamate cysteine ligase, which is the rate-limiting enzyme of glutathione synthesis. The present study used BSO to investigate whether the protective effects of captopril were related to an increase in glutathione synthesis. Pre-treatment with BSO inhibited the protective effects of captopril on dRib-induced cytotoxicity. Co-administration of $\mathrm{dRib}$ and BSO appeared to increase cell death, as compared with treatment with dRib alone; however, these apparent results were not statistically significant. Treatment with captopril significantly reduced the cytotoxicity caused by the co-administration of dRib and BSO. BSO alone did not significantly alter cell viability, as compared with the control (Fig. 6A). Treatment with BSO suppressed the captopril-induced prevention of intracellular glutathione depletion caused by dRib. Co-treatment with $\mathrm{dRib}$ and BSO increased the depletion of glutathione, as compared with dRib alone. Addition of captopril restored the glutathione depletion caused by co-treatment with dRib and BSO. Unlike the Trypan blue exclusion, the glutathione assay demonstrated that BSO alone significantly decreased the intracellular levels of glutathione, as compared with the control. These effects were not reversed by the addition of captopril (Fig. 6B).

dRib-induced protein glycation is not suppressed by treatment with captopril. The present study assessed the formation of dicarbonyl and AGE in order to investigate whether captopril is able to inhibit the dRib-induced protein glycation in vitro. Protein-bound dicarbonyl and AGE formation were measured using Girard-T reagent and fluorometry, respectively. Following 3 days incubation of albumin with 10, 20, or $30 \mathrm{mM} \mathrm{dRib,} \mathrm{dRib} \mathrm{dose-dependently} \mathrm{increased} \mathrm{dicarbonyl}$
Table II. Relative intracellular levels of reactive oxygen species in the control and dRib-treated Syrian hamster insulinoma HIT-T15 cells, with or without CAP treatment.

Group

Relative fluorescence (fold change from control)

Control 1.0

$50 \mathrm{mM}$ dRib $11.9 \pm 2.5^{\mathrm{a}}$

$1 \mathrm{mM} \mathrm{CAP}+50 \mathrm{mM} \mathrm{dRib}$

$1.8 \pm 0.4^{\mathrm{b}}$

Data are expressed as the mean \pm standard error of four independent experiments. ${ }^{a} \mathrm{P}<0.01$, vs. the control group, and ${ }^{\mathrm{b}} \mathrm{P}<0.01$, vs. the $50 \mathrm{mM}$ dRib group, as determined by one-way analysis of variance and Duncan's post hoc test. dRib, 2-deoxy-D-ribose; CAP, captopril.

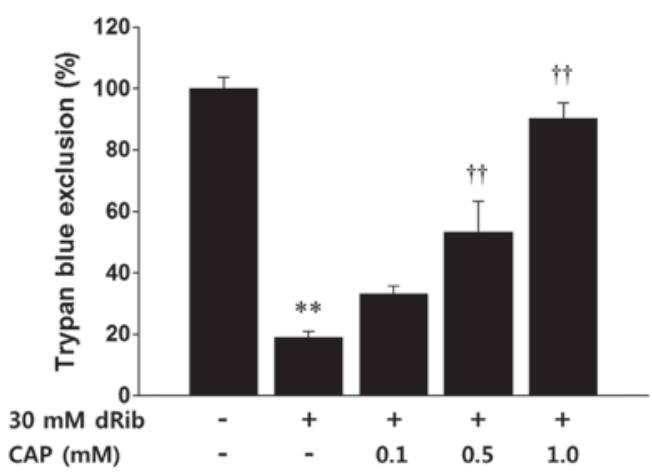

Figure 1. Effects of treatment with captopril (CAP), 2-deoxy-D-ribose (dRib)-induced cell death. The Syrian hamster insulinoma HIT-T15 cells were pre-incubated with CAP at the indicated concentrations for $30 \mathrm{~min}$ prior to being cultured with $30 \mathrm{mM}$ dRib for $24 \mathrm{~h}$. Cell viability was determined by trypan blue exclusion. The data are presented as the mean \pm standard error of the percentage of viable cells, as compared with the controls. This experiment was performed twice, in quadruplicate. ${ }^{* *} \mathrm{P}<0.01$, vs. the control group, and ${ }^{\dagger} \mathrm{P}<0.01$, vs. the $30 \mathrm{mM}$ dRib group, as determined by one-way analysis of variance and Duncan's post hoc test.

formation and AGE fluorescence. Treatment with captopril did not suppress these dRib-induced effects (Fig. 7A and B).

\section{Discussion}

Our previous study investigated the mechanism underlying dRib-induced damage in a pancreatic $\beta$-cell line (2). In our previous study, the metal chelator diethylenetriaminepentaacetic acid (DTPA) suppressed dRib-induced increases in intracellular ROS in HIT-T15 cells; however, DTPA did not reduce the formation of dRib-mediated dicarbonyl and AGE in vitro. Pyridoxamine, which is a post-Amadori inhibitor, was able to decrease the dRib-induced formation of dicarbonyl and AGE; however, pyridoxamine did not suppress the dRib-induced production of intracellular ROS. Both DTPA and pyridoxamine protected the HIT-T15 cells against dRib-induced cytotoxicity and apoptosis. These results suggested that both oxidative stress and protein glycation are important mechanisms underlying dRib-induced $\beta$-cell damage.

The present study demonstrated that captopril did not suppress dRib-induced increases in protein-bound dicarbonyl 

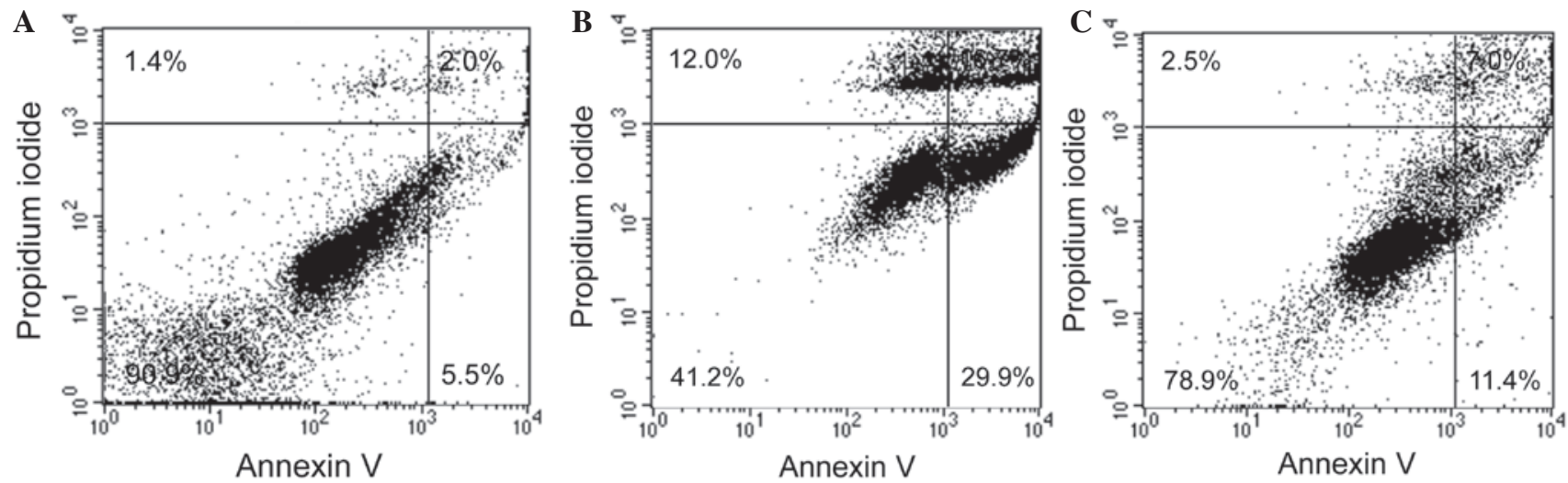

Figure 2. Effects of captopril (CAP) treatment on 2-deoxy-D-ribose (dRib)-induced apoptosis in Syrian hamster insulinoma HIT-T15 cells. The cells were pre-incubated with $1.0 \mathrm{mM}$ CAP for $30 \mathrm{~min}$, prior to being cultured with $50 \mathrm{mM}$ dRib for $24 \mathrm{~h}$. The cells were stained with Annexin V and propidium iodide and analyzed by flow cytometry. The graph is representative of four independent experiments. (A) Control; (B) $50 \mathrm{mM} \mathrm{dRib}$; and (C) $1.0 \mathrm{mM}$ CAP + $50 \mathrm{mM}$ dRib.

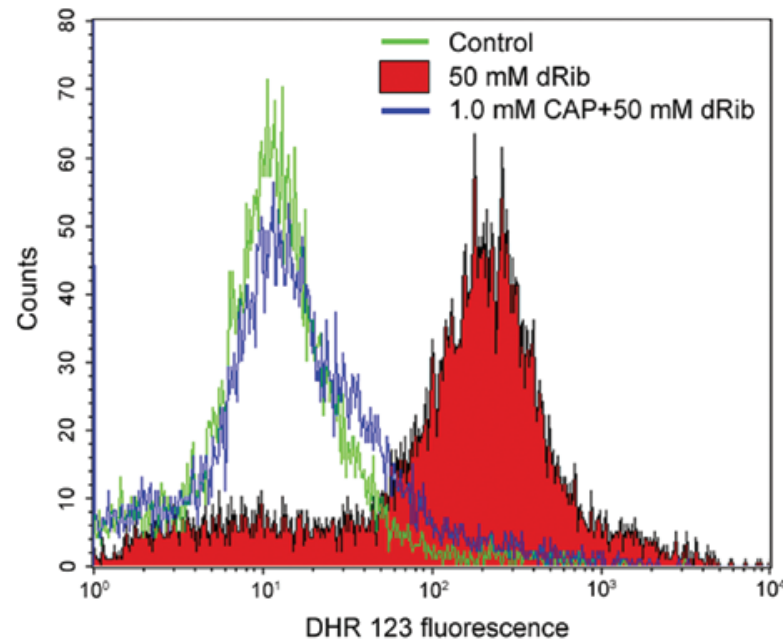

Figure 3. Effects of captopril (CAP) treatment on the 2-deoxy-D-ribose (dRib)-induced increase in intracellular levels of reactive oxygen species (ROS). The cells were pre-incubated with $1.0 \mathrm{mM} \mathrm{CAP}$ for $30 \mathrm{~min}$ prior to being cultured with $50 \mathrm{mM}$ dRib for $6 \mathrm{~h}$. The levels of ROS were quantified by flow cytometry using the ROS-sensitive dye DHR 123 . The cells were incubated with $5 \mathrm{mM}$ DHR 123 during the final $30 \mathrm{~min}$. The histogram is representative of four independent experiments.

concentration and AGE fluorescence. Dicarbonyl is the monosaccharide-derived precursor of AGE (12); however, captopril does not inhibit protein glycation. In the present study, captopril decreased the intracellular levels of oxidative stress via the replenishment of depleted glutathione. The mechanism underlying the effects of captopril, which is thought to protect against oxidative stress, may involve an increase in the synthesis of intracellular GSH, due to the fact that BSO, a specific inhibitor of GCL, suppressed the protective effects of captopril on dRib-induced cytotoxicity and glutathione depletion. Therefore, an increase in glutathione synthesis, rather than an inhibition of protein glycation, may be the mechanism underlying the protective effects of captopril in $\mathrm{dRib}$-induced $\beta$-cell damage.

Previous studies have reported that captopril exhibits antioxidative effects $(7,9,13,14)$. The majority of these studies have suggested that captopril exerts direct ROS-scavenging

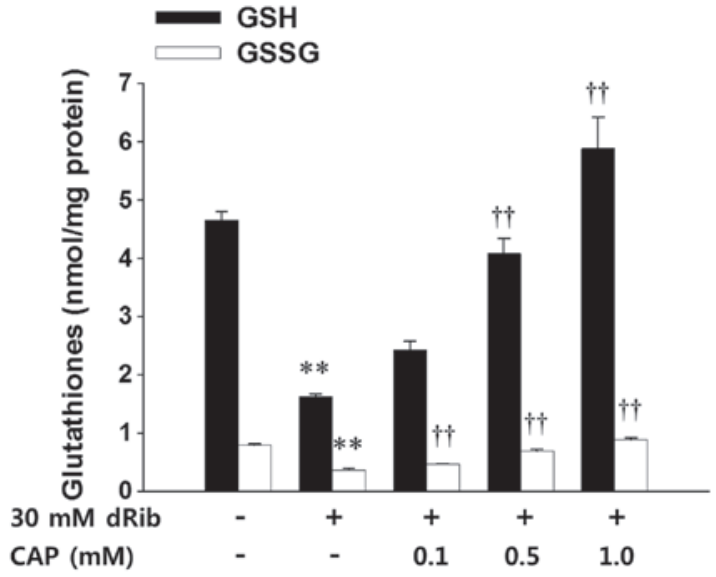

Figure 4. Effects of captopril (CAP) treatment on 2-deoxy-D-ribose (dRib)-induced depletion of intracellular reduced (GSH) and oxidized (GSSG) glutathione content. The Syrian hamster insulinoma HIT-T15 cells were pre-incubated with $0.1,0.5$, or $1.0 \mathrm{mM} \mathrm{CAP}$ for $30 \mathrm{~min}$ prior to being cultured with $30 \mathrm{mM}$ dRib for $6 \mathrm{~h}$. The intracellular glutathione concentrations were measured using a Glutathione Assay kit. The data are presented as the mean \pm standard error. ${ }^{* *} \mathrm{P}<0.01$, vs. the control group, and ${ }^{{ }^{\dagger} \mathrm{P}}<0.01$, vs. the $30 \mathrm{mM}$ dRib group, as determined by one-way analysis of variance and Duncan's post-hoc test.

activity via its sulfhydryl group $(7,9,13)$. Using electron spin resonance spectroscopy, the present study also investigated the ROS-scavenging effects of captopril in a cell-free system (data not shown). However, these results did not support the hypothesis that ROS-scavenging activity contributes to the protective effects of captopril against dRib-induced oxidative damage in $\beta$-cells. Pre-treatment with captopril increased the intracellular concentrations of both GSH and GSSG. These results indicated that captopril regulates the total intracellular levels of glutathione rather than the intracellular glutathione redox potential. Treatment with BSO inhibited the protective effects of captopril on dRib-induced glutathione depletion and cytotoxicity. These results demonstrated that intracellular glutathione synthesis is an important mechanism underlying the protective effects of captopril on dRib-induced $\beta$-cell damage. However, the results of the present study did not identify a specific mechanism to explain the captopril-induced 
A

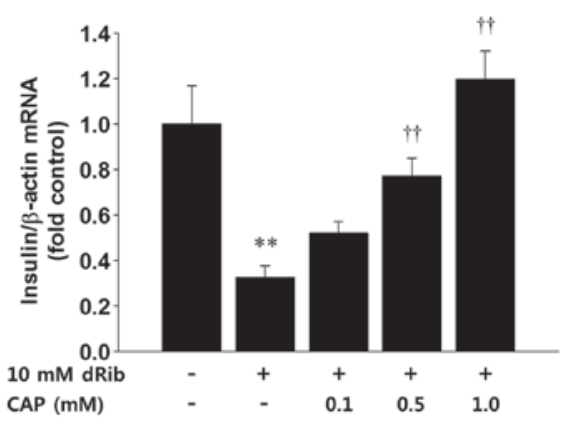

B

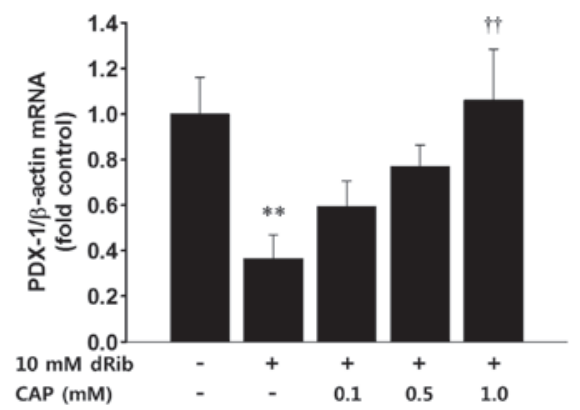

C

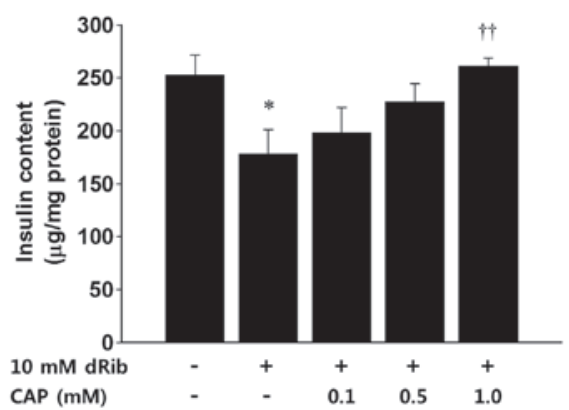

Figure 5. Effects of captopril (CAP) treatment on the 2-deoxy-D-ribose (dRib)-induced decrease in the mRNA expression levels of (A) insulin, and (B) pancreatic and duodenal homeobox 1 (PDX-1), and the (C) insulin content in the rat islets. The isolated islets were pre-incubated with CAP at the indicated concentrations for $30 \mathrm{~min}$ prior to being cultured with $10 \mathrm{mM} \mathrm{dRib}$ for $6 \mathrm{~h}$. Total RNA of the islets was extracted, and the mRNA expression levels of (A) insulin and (B) PDX-1 were analyzed by reverse transcription-quantitative polymerase chain reaction (RT-qPCR). (C) The proteins were extracted, and the insulin content was measured by ELISA. The data are presented as the mean \pm standard error. These experiments were performed twice, in quadruplicate. ${ }^{*} \mathrm{P}<0.05$ and ${ }^{* *} \mathrm{P}<0.01$, vs. the control group, and ${ }^{\dagger} \mathrm{P}<0.01$, vs. the $10 \mathrm{mM}$ dRib group, as determined by one-way analysis of variance and Duncan's post hoc test.

A

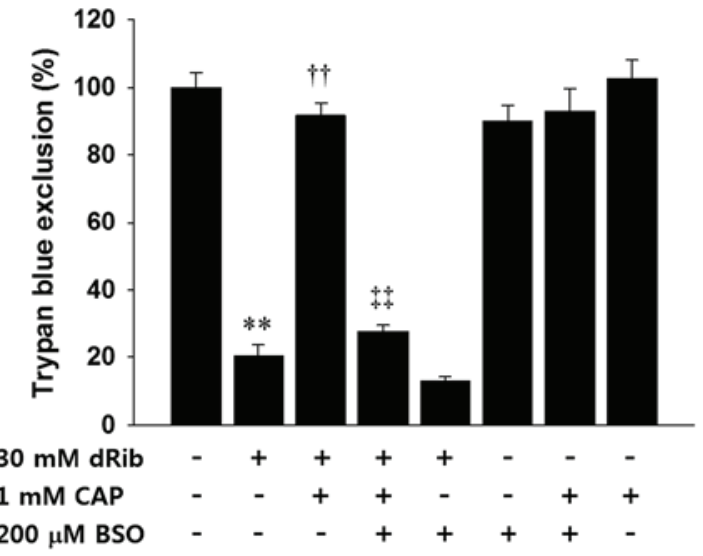

B

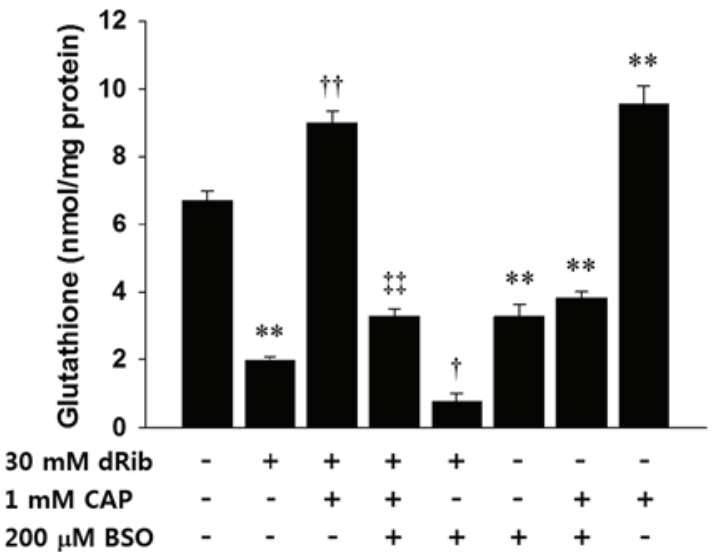

Figure 6. Effects of 1-buthionine-sulfoximine (BSO) on the protective effects of captopril (CAP) treatment on (A) 2-deoxy-D-ribose (dRib)-mediated cytotoxicity and (B) glutathione depletion in the Syrian hamster insulinoma HIT-T15 cells. The cells were pre-incubated with $200 \mu \mathrm{M}$ BSO for 30 min, and $1.0 \mathrm{mM}$ CAP was added to the medium containing $30 \mathrm{mM}$ dRib. The cultures were incubated for (A) $24 \mathrm{~h}$ or (B) $6 \mathrm{~h}$. (A) Cytotoxicity was assessed by Trypan blue exclusion. (B) The intracellular glutathione concentrations were measured using a Glutathione Assay kit. These experiments were performed twice, in quadruplicate. The data are presented as the mean \pm standard error. ${ }^{* *} \mathrm{P}<0.01$ vs. control; ${ }^{\dagger} \mathrm{P}<0.05$ and ${ }^{\dagger \dagger} \mathrm{P}<0.01$ vs. $30 \mathrm{mM} \mathrm{dRib}$ alone; ${ }^{*+} \mathrm{P}<0.01$ vs. $30 \mathrm{mM}$ $\mathrm{dRib}+1 \mathrm{mM}$ CAP, as determined by one-way analysis of variance and Duncan's post hoc test.
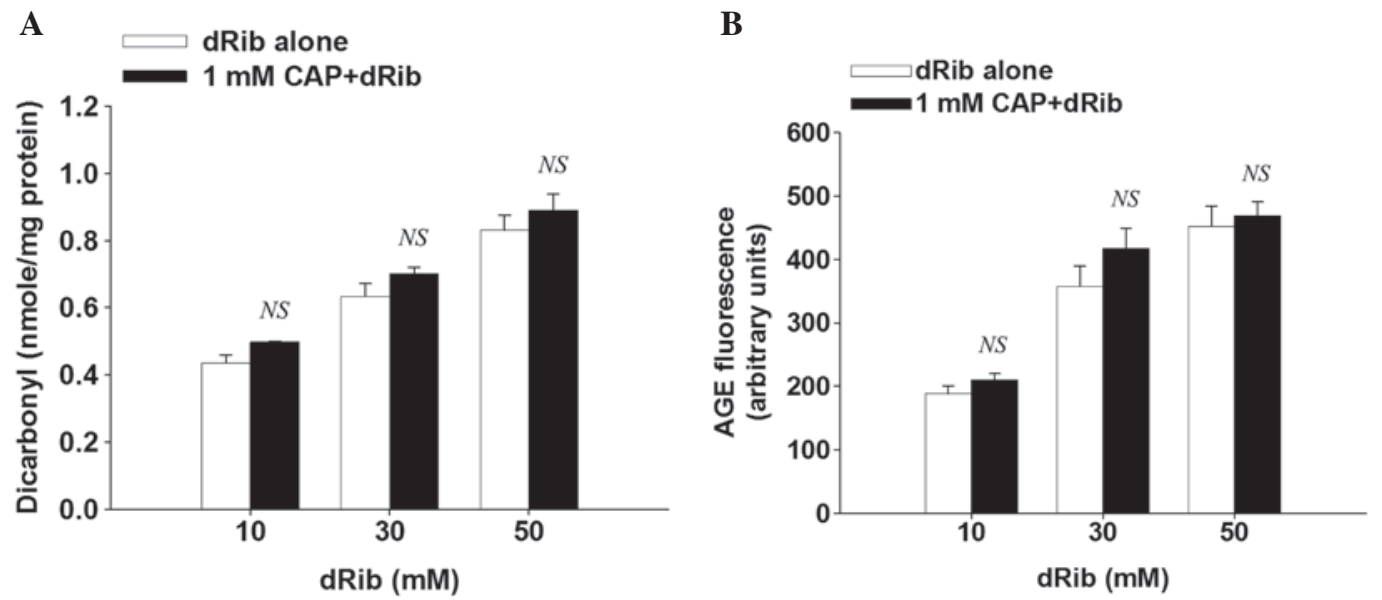

Figure 7. Inhibitory effects of captopril (CAP) on the formation of (A) protein-bound dicarbonyl and (B) advanced glycation end products. Bovine serum albumin $(10 \mathrm{mg} / \mathrm{ml})$ was incubated with 10,30 , or $50 \mathrm{mM}$ 2-deoxy-D-ribose (dRib) at $37^{\circ} \mathrm{C}$ for 3 days in the presence or absence of CAP. Dicarbonyl concentration was estimated by adduct formation with the Girard-T reagent. Advanced albumin glycation was determined by measuring the fluorescence intensity (excitation and emission wavelength of 350 and $450 \mathrm{~nm}$, respectively), as compared with a non-incubated blank containing the protein, dRib, and CAP. The data are presented as the mean \pm standard error. This experiment was performed twice, in quadruplicate. NS, no significant difference, as compared with the dRib-alone group, as determined by Student's t test. 
increase in glutathione synthesis. The possible mechanisms underlying glutathione synthesis are increased activity and expression levels of GCL, and/or increased delivery of GCL substrates. Further research is required in order to further elucidate this mechanism.

Glucose toxicity is defined as the non-physiological and potentially irreversible $\beta$-cell damage caused by chronic exposure to supraphysiological glucose concentrations (3). Long-term stimulation via exposure to high glucose concentrations causes ROS production in pancreatic $\beta$-cells, and this oxidative stress suppresses the mRNA expression levels of PDX-1, and PDX-1 binding to the insulin gene promoter. As a result, insulin gene expression and secretion decrease $(15,16)$. In the present study, dRib stimulation decreased the mRNA expression levels of PDX-1 and insulin in isolated islets, and treatment with captopril reversed these dRib-induced effects. These results suggested that $\mathrm{dRib}$ is able to induce $\beta$-cell damage, as does high glucose concentrations in rat islets. It is also possible that captopril may prevent glucose toxicity.

The present study had limitations. Captopril was developed for the purpose of inhibiting ACE; however, the present study did not evaluate the role of the inhibition of ACE in preventing $\mathrm{dRib}$-induced $\beta$-cell damage. The present study investigated the extent of protein glycation using bovine serum albumin in vitro. Technical issues disturbed the measurement of the concentration levels of intracellular protein-bound dicarbonyl and AGE in $\beta$-cells. The results of the present study did not successfully elucidate the mechanism underlying dRib-induced oxidative stress. Our previous study reported that intracellular glutathione depletion was an important factor in dRib-mediated oxidative damage (17). Both our previous and present studies have prompted further investigation into the mechanism underlying $\mathrm{dRib}$ depletion of intracellular glutathione, in order to elucidate the mechanisms underlying for the protective effects of captopril on dRib-induced $\beta$-cell damage.

In conclusion, the results of the present study demonstrated that captopril suppressed dRib-induced oxidative damage by increasing the levels of glutathione synthesis in $\beta$-cells. Protein glycation was not associated with the protective effects of captopril. The ROS-scavenging activity of captopril did not appear to be important for the prevention of dRib-triggered $\beta$-cell damage. Further research is required in order to identify the mechanism underlying the captopril-induced increase in intracellular glutathione synthesis. Captopril may attenuate oxidative stress in pancreatic $\beta$-cells and may prevent glucose toxicity in type 2 diabetes. Captopril is used in the treatment of high blood pressure, and the results of the present study suggest that it may have potential as a novel treatment for preventing $\beta$-cell failure in patients with type 2 diabetes.

\section{Acknowledgements}

The present study was supported by research grants from Jeju National University Hospital and the Korean Diabetes Association in 2010.

\section{References}

1. Monnier VM: Nonenzymatic glycosylation, the Maillard reaction and the aging process. J Gerontol 45: B105-B111, 1990.

2. Koh G, Lee DH and Woo JT: 2-Deoxy-D-ribose induces cellular damage by increasing oxidative stress and protein glycation in a pancreatic beta-cell line. Metabolism 59: 325-332, 2010.

3. Robertson RP, Harmon J, Tran PO, Tanaka Y and Takahashi H: Glucose toxicity in beta-cells: Type 2 diabetes, good radicals gone bad, and the glutathione connection. Diabetes 52: 581-587, 2003.

4. Brownlee M: Biochemistry and molecular cell biology of diabetic complications. Nature 414: 813-820, 2001.

5. Scheen AJ: Prevention of type 2 diabetes mellitus through inhibition of the Renin-Angiotensin system. Drugs 64: 2537-2565, 2004.

6. DeFronzo RA: Lilly lecture 1987. The triumvirate: Beta-cell, muscle, liver. A collusion responsible for NIDDM. Diabetes 37: 667-687, 1988 .

7. Mak IT, Freedman AM, Dickens BF and Weglicki WB: Protective effects of sulfhydryl-containing angiotensin converting enzyme inhibitors against free radical injury in endothelial cells. Biochem Pharmacol 40: 2169-2175, 1990.

8. Hayek T, Attias J, Smith J, Breslow JL and Keidar S: Antiatherosclerotic and antioxidative effects of captopril in apolipoprotein E-deficient mice. J Cardiovasc Pharmacol 31: 540-544, 1998.

9. Andreoli SP: Captopril scavenges hydrogen peroxide and reduces, but does not eliminate, oxidant-induced cell injury. Am J Physiol 264: F120-F127, 1993.

10. Lacy PE and Kostianovsky M: Method for the isolation of intact islets of Langerhans from the rat pancreas. Diabetes 16: 35-39, 1967.

11. Mitchel RE and Birnboim HC: The use of Girard-T reagent in a rapid and sensitive methods for measuring glyoxal and certain other alpha-dicarbonyl compounds. Anal Biochem 81: 47-56, 1977.

12. Degenhardt TP, Thorpe SR and Baynes JW: Chemical modification of proteins by methylglyoxal. Cell Mol Biol (Noisy-le-grand) 44: 1139-1145, 1998.

13. Bagchi D, Prasad R and Das DK: Direct scavenging of free radicals by captopril, an angiotensin converting enzyme inhibitor. Biochem Biophys Res Commun 158: 52-57, 1989.

14. Chen SX, Song T, Zhou SH, Liu YH, Wu SJ and Liu LY: Protective effects of ACE inhibitors on vascular endothelial dysfunction induced by exogenous advanced oxidation protein products in rats. Eur J Pharmacol 584: 368-375, 2008.

15. Harmon JS, Gleason CE, Tanaka Y, Oseid EA, Hunter-Berger KK and Robertson RP: In vivo prevention of hyperglycemia also prevents glucotoxic effects on PDX-1 and insulin gene expression. Diabetes 48: 1995-2000, 1999.

16. Robertson RP: Chronic oxidative stress as a central mechanism for glucose toxicity in pancreatic islet beta cells in diabetes. J Biol Chem 279: 42351-42354, 2004.

17. Koh G, Kim MK, Yang EJ and Lee DH: Gliclazide does not fully prevent 2-deoxy-D-ribose-induced oxidative damage because it does not restore glutathione content in a pancreatic $\beta$-cell line. Oxid Med Cell Longev 2012: 390678, 2012. 